\title{
Cultura material da escola: entram em cena as carteiras
}

\section{Material culture of the school: the portfolio comes into play}

\author{
Raquel Xavier de Souza Castro ${ }^{1}$ \\ Vera Lucia Gaspar da Silva²
}

\begin{abstract}
RESUMO
Carteiras escolares: objeto de pesquisa sobre a história da cultura material da escola catarinense. A intenção deste artigo é apresentar alguns resultados referentes a essa pesquisa. Com o trabalho, busca-se identificar aspectos que caracterizem este mobiliário no início da organização das escolas primárias em Santa Catarina. Fontes da pesquisa: legislação, pareceres de professores, relatórios de inspetores, receitas de compras da então Província, além de ícones da época. O advento do ensino da escrita como tarefa escolar é um divisor de águas na configuração material do espaço escolar. A reflexão é balizada por referências a métodos de ensino, considerados articuladores da presença ou alteração de determinado mobiliário no interior das salas de aula. Em termos teóricos, tem se mobilizado um repertório que incide particularmente na história da educação, na cultura material da escola e em referências aos inícios da escolarização, principalmente na Europa e nos Estados Unidos.

Palavra-chave: carteiras escolares; cultura material da escola; métodos de ensino; mobiliário escolar.
\end{abstract}

\footnotetext{
ABSTRACT

The School Desks: the research's object about the history of material culture of Santa Catarina's schools. The aim of this article is to present some results related to this research and to identify some aspects that char-

1 Mestre em Educação pela Universidade Federal de Santa Catarina (UFSC), Brasil.

2 Professora Doutora da Universidade Federal de Santa Catarina (UFSC), Brasil.
} 
acterize this furniture at the begining of the organization of the primary schools in the state of Santa Catarina. The Research Sources: legislation, teachers' opinions, reports of inspectors, incomes, besides icons of this period. The advent of teaching writing in the schools is a watershed in the schools setting material and furniture. The reflection is based in references of methods of teaching considered articulators of presence or alteration of certain determinate furniture inside the classrooms. In theoretical terms, it has been mobilized a repertory that happens particularly in the history of education, schools' material culture and in references to beginnings of schooling, especially in Europe and the United States.

Keywords: school desks; school's material culture; teaching methods; school furniture.

Para cúmulo de desespero, vi através das vidraças da escola, no claro azul do céu, por cima do morro do Livramento, um papagaio de papel, alto e largo, preso de uma corda imensa, que bojava no ar, uma coisa soberba. E eu na escola, sentado, pernas unidas, com o livro de leitura e a gramática nos joelhos.

O texto acima, extraído do Conto de Escola, de Machado de Assis, está ambientado no ano de 1840 e trata da infância de Pilar, no Rio de Janeiro. O menino entediado, na escola, um livro sobre os joelhos e mais a gramática, enxergava por cima do Morro do Livramento um papagaio de papel ${ }^{3}$.

Esta sugestiva literatura, que até poderia acionar a fantasia, na verdade tem aqui um propósito um pouco mais pragmático: além de fazer um retrato de uma cena escolar, fornece alguns indícios sobre mobiliário escolar, a famosa "carteira" que, como hoje, servia para acomodar alunos e livros. Pois essa carteira sofreu mudanças significativas. No caso em cena, é provável que ela não passasse de um banco ou cadeira e mesa, pois o que então havia era uma cadeira ou banco; para apoio, o aluno utilizava o próprio corpo. Enquanto se ocupava apenas do ensino da leitura, o apoio para o impresso poderia ser o próprio colo; a cadeira ou o banco não precisava de "seu par", em formato de mesa, conjunto que mais tarde viria a caracterizar com tanta força a escola.

$\mathrm{Na}$ busca pelas origens desse objeto ${ }^{4}$, a carteira escolar, recorre-se a um

3 Papagaio de papel: brinquedo infantil, formado de armação de varetas, coberta de papel fino, e que, por meio duma linha, se empina, mantendo-se no ar (AURÉLIO, 1985, p. 349).

4 Ao longo do texto utilizam-se aleatoriamente os termos objetos, utensílios ou artefatos escolares como similares. Isto tem sido recorrente na bibliografia que trata da temática. 
conjunto de estudos. E em Daniel Roche ${ }^{5}$ encontram-se informações que ajudam a compreender a "origem das coisas" que se tornariam banais no cotidiano da sociedade ocidental. Ao falar sobre a história da mesa, Daniel Roche revela que durante muito tempo se viveu bem sem ela. Após sua invenção e incorporação, considerada moderna, ela passou a ditar maneiras de civilidade e a configurar o mobiliário indispensável na maior parte das residências

da habitação do campo à morada aristocrática, a diferença era grande, mas em ambos os casos a mesa respondia a uma necessidade na relação do homem com o homem: nela a alimentação foi transfigurada em relações sociais (ROCHE, 1998, p. 233).

Para além de cenário para encontros e refeições, a mesa passou a desempenhar outros papéis na sua função de apoio: trabalho, jogos, lazer...

Com relação à origem das cadeiras, Daniel Roche explica que estas se relacionam com "a necessidade de repouso com menos evidência de que a cama" e também com a importância social.

Na corte de Luís XIV, toda a gente se senta conforme o seu estatuto: o rei tem direito a uma poltrona - uma cadeira de braços; o delfim, a uma cadeira de espaldar; os príncipes de sangue, ao tamborete alto; os duques e pares, aos tamboretes normais; os cortesãos, a um banco articulado" (ROCHE, 1998, p. 235).

Embora na vida privada ou em cenas públicas as cadeiras pudessem ter relação com o conforto e com o status social, na cena escolar elas não respondiam pela mesma função. Bancos e cadeiras ordenavam espaços e sujeitos dentro de um universo delimitado. Na escola, mesa e cadeira encontraram força singular que as transformaram em objetos com atuação direta na higiene do corpo, na disciplina, no conforto e na aprendizagem. Perpetuaram-se como objeto fundamental para um bom ensino. Algumas delas, no entanto, ganharam um real espaço no ensino quando se tornaram necessárias como apoio para escrever, pois até então ensinava-se, primordialmente, a ler.

5 Trata-se da obra História das Coisas Banais cuja referência completa se encontra ao final deste trabalho. 
Para Jean Baudrillard (2006), a dimensão real dos objetos e dos móveis é prisioneira da dimensão moral que tem que "significar". Embora o autor faça referência aos utensílios domésticos, é pertinente estender a reflexão para o espaço escolar. Os usos da carteira escolar foram tomando tal proporção nas salas de aula que professores e alunos pareciam prisioneiros dessa "dimensão moral", um enredamento no qual parece ter havido pouco espaço ou autonomia para se alterar a organização espacial.

Segundo Rogério Fernandes, o ensino da leitura nas escolas é anterior ao ensino da escrita:

Também no universo social da burguesia mercantil e dos "ofícios de pena", escrivães do serviço público e privado, constituía a leitura um capital cultural de valor considerável. No contexto das atividades de comércio e serviços, a leitura ocupava um espaço nobre do currículo do ensino elementar. Até então, o ensino da escrita não acompanhava necessariamente o da leitura. Ainda menos o do cálculo, a tal ponto que na Lisboa quinhentista existiam especialistas em escrever e em calcular (FERNANDES, 1998, p. 8).

Jean Hébrard também assinala esta passagem. Para o autor:

Ler, escrever, contar não foram sempre os fundamentos obrigatórios da instrução popular. As escolas, tanto as pertencentes ao mundo da reforma protestante quanto as do mundo da contra-reforma católica, assumiram tardiamente o objetivo de conduzir as crianças da cidade e, depois, as do campo, para além do "somente ler" que, no fim do século XVI, parecia ser o horizonte intransponível da instrução cristã. Aprender a escrever para fazer contas e para redigir algumas cartas comerciais exigidas desde o século XVII pela boa direção de uma loja ou de uma barraca não era uma coisa fácil (HÉBRARD, 2001, p. 116).

Estas referências ajudam a compreender as diversas transformações do mobiliário escolar. No caso do apoio para alunos de escolas que ensinavam somente a ler, as mesas eram dispensáveis. O colo ou os joelhos, por exemplo, serviam para tal tarefa, que é o que mostra a passagem de Machado de Assis que abre este trabalho.

Com a chegada do ensino da escrita, passou a ser fundamental ter-se um apoio para colocar a lousa, a ardósia ou o papel para escrever. A mesa ou a carteira 
foram ganhando espaço nas salas de aula, acompanhando métodos de ensino e se estabeleceram como objetos potencializadores da escrita. A base material da escola acompanharia, ao mesmo tempo em que as indica, as alterações no universo escolar. Estudos acerca de alterações desta natureza podem, então, contribuir para compreender situações que se enredam na história da forma escolar ${ }^{6}$.

Conforme Rosa Fátima de Souza, "o estudo histórico dos materiais escolares pode ser um instrumento valioso para se decifrar a cultura escolar à medida que as práticas são mediatizadas, em muitos sentidos, pelas condições materiais". Ainda segundo a autora, "Da articulação entre saberes, práticas e materiais escolares é que se concretiza o fazer pedagógico que está no cerne da compreensão do funcionamento interno da escola e de sua função no tempo e espaço sócio-histórico" (SOUZA, 2007, p. 179-180).

\section{Buscando pistas em território catarinense}

O estado de Santa Catarina serve de referência para o estudo que deu origem às reflexões aqui apresentadas. No esforço de se entender o quadro material da escola catarinense da metade do século XIX ao início do século XX, é comum recorrer-se aos relatórios de inspetores. Neste estado, estas "autoridades do ensino" denunciavam com muito afinco a precariedade das condições do espaço e dos materiais com os quais os professores davam suas aulas. A realidade material destas escolas constitui aspecto importante para a compreensão de seu funcionamento interno e sua localização nas políticas públicas. Num período no qual a questão da educação escolar ocupava espaços nos discursos dos governantes, é de se estranhar a denúncia sobre precariedade material.

A estrutura material da escola é "um lugar", "um espaço peculiar e relevan$t e$ ". É nela também que se educa por suas presenças e ausências. Esta estrutura material e o uso que dela se faz são componentes, nem sempre explicitados, do trabalho educativo. Para Antonio Viñao Frago, neste espaço:

Se formam as estruturas mentais básicas das crianças, adolescentes e jovens. Estruturas mentais conformadas por um espaço que, como todos,

6 Aqui adotamos como apoio teórico, particularmente, o trabalho de Guy Vincent; Bernard Lahire e Daniel Thin (2001), sobre a história e a teoria da forma escolar, publicado em 2001 no periódico Educação em Revista (Belo Horizonte/MG: Faculdade de Educação da Universidade Federal de Minas Gerais, n. 33, p. 7-47, jun. 2001. 
socializa e educa, mas que, diferentemente de outros, situa e ordena com essa finalidade específica a tudo e a todos quantos nele se encontram (FRAGO, 2001, p. 64).

Para este autor, "todo educador, se quiser sê-lo, tem de ser arquiteto. De fato, ele sempre o é, tanto se ele decide modificar o espaço escolar, quanto se o deixa tal e qual está dado" (2001, p. 75). Nesta esteira, pode-se afirmar que, como parte integrante desta base material, as carteiras escolares não são dispostas ao acaso nas salas de aula. A disposição guarda intenções previamente estabelecidas, ou pela vontade do professor e acompanhada de métodos de ensino, manuais, regulamentos, ou por lei. Mas a evidência mais forte que se encontrou foi a da relação de alterações neste mobiliário para atender a "demandas" ou a particularidades didático-pedagógicas dos métodos de ensino.

Para Maria de Fátima Machado:

A distribuição espacial dos alunos foi facilmente reconhecida como norma de método de ensino. Ela atravessa toda a história da educação, desde o mútuo ao simultâneo, reclamando os diferentes métodos, diferentes espaços, capazes de suportar as diferentes especificidades de cada método, nomeadamente na relação entre o tamanho dos grupos e o dimensionamento da sala de aula (MACHADO, 2004, p. 11).

A partir desta evidência, fizeram-se investimentos no sentido de identificar formas e funções do mobiliário escolar nos anos oitocentos na Província de Santa Catarina, relacionando-os aos métodos de ensino então adotados ou anunciados. No primeiro ato da Assembléia de Santa Catarina sobre a instrução pública, já foram citados os métodos que deveriam ser desenvolvidos nas escolas das primeiras letras: individual e mútuo. Este ato (Lei n. 35, de 14 de maio de 1836), que trata da organização da instrução pública, embora faça referência aos métodos, trata principalmente da forma de contratação, remuneração e da carreira como servidor público dos professores. A leitura deste texto revela (em seu artigo $\mathrm{n}^{\circ} 16$ ) o vínculo da remuneração dos professores com o método de ensino aplicado nas aulas:

Art. 16 - Nas Escolas de Instrução primaria pelo methodo individual se ensinará a Ler, escrever, as quatro operações de Arithmetica, Grammatica 
da Lingoa Nacional, e a Doutrina Christã. Os seus Professores terão ordenados nas Villas dusentos e quarenta mil reis, e nas Freeguesias e Curatos dusentos mil reis. Nas de ensino mutuo se ensinará pelo methodo de Lencaster [sic] e seus Professores terão de ordenados na Cidade tresentos e sessenta mil reis, e nas Villas tresentos mil reis. O Presidente da Provincia designará os Compêndios, e Syllabarios porque se deva ensinar tanto em humas como em outras escolas; e dará quaesquer instrucções que julgar necessárias à regularidade do ensino (COLLEÇÃO DAS LEIS DA PROVÍNCIA DE SANTA CATHARINA DOS ANOS DE 1835 a 1853, p. 57$)^{7}$

Percebe-se que a remuneração do professor que ensina pelo método de ensino individual é inferior à daquele que ensina pelo método mútuo. O capítulo $1^{\circ}$ da Lei $n^{\circ} 71$ (de 28 de abril de 1837), que trata da "Despesa referente à Instrução Pública", mostra quanto a Província de Santa Catarina gastava com o pagamento dos professores.

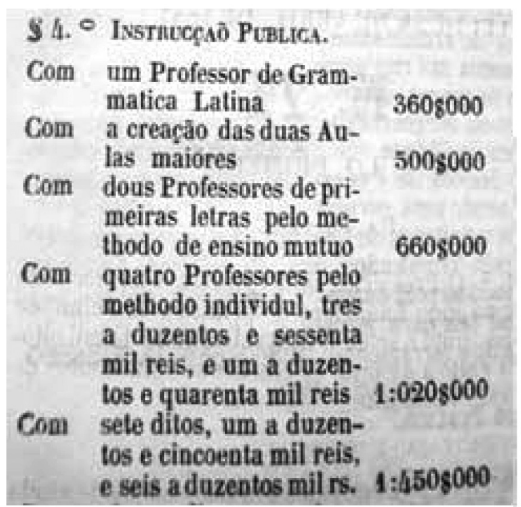

FIGURA 1- REMUNERAÇÃO DOS PROFESSORES.

FONTE: Colleção das Leis da Província de Santa Catharina dos anos de 1835 a 1853, p. 163.

Os dados da figura 1 mostram também que o número de escolas que aplicavam o método de ensino mútuo era muito inferior ao das que desenvolviam seu ensino com o método de ensino individual, praticamente o dobro de escolas, pois o método mútuo só poderia ser aplicado "na Cidade, nas Villas, e naquellas em que taes escolas, estando por leis authorisadas, se achem actualmente

7 Transcrição na íntegra, obedecendo à norma ortográfica da época. 
providas. As que houverem nas Freguesias, ou Curatos serão reduzidas às do ensino individual" (COLLEÇÃO DAS LEIS DA PROVÍNCIA DE SANTA CATHARINA DOS ANOS DE 1835 a 1853, p. 55). Há aqui um conjunto de elementos a serem explorados: seria esta uma forma de estimular a adoção do ensino mútuo? Quais os critérios para definir ou decidir entre um ou outro método? Era esta uma escolha dos docentes ou uma determinação do órgão central?

$\mathrm{O}$ trabalho de garimpagem de dados exige que se mantenha um olhar aguçado tanto sobre as presenças quanto sobre as ausências. Por exemplo, a Lei $\mathrm{n}^{\circ} 35$, de 1836, indicada por Neide Fiori como primeiro ato sobre a instrução pública da Assembleia de Santa Catarina, não se refere especificamente ao mobiliário necessário para cada método de ensino; mas as pistas que deixa são de que cada método tinha, além de sua maneira de ensinar, também seu próprio mobiliário. Na passagem abaixo, datada de $1^{\circ}$ de julho de 1836 , o professor público de Primeiras Letras, Inácio José de Carvalho, da Freguesia de Santa Ana de Vila Nova, solicita mobiliário para aplicar o método mútuo e ao mesmo tempo pede que se cumpram as normas (o salário estipulado na Lei n. 35), como é possível atestar com a leitura:

Comissão de Fazenda e Orçamento a quem foi remetido o requerimento que fez à Província, Inácio José de Carvalho Professor Público de Primeiras Letras, pelo methodo individual, da Freguesia de Santa Ana de Vila-Nova, em que pede casa, mesas, bancos e etc. para a aula, a exemplo do que recebeu a Vila de Laguna: cumpre declarar que mandando dar os preparos para as aulas de Ensino Mútuo, nada ordenou para as de ensino individual, portanto não podem a favor do pedir cobrar as normas que alega (CENTRO DE MEMÓRIA DA ASSEMBLÉIA LEGISLATIVA, doc. 33, Pareceres, 1835/1841, p. 21).

O parecer escrito pelo professor em 1836 deixa entrever que existia um mobiliário específico para o Ensino Mútuo - mesa e banco. Outro fato interessante desse documento diz respeito às "normas" mencionadas pelo professor, e que fazem referência provavelmente à Lei ${ }^{\circ} 35$. Nesta, o salário do professor de Ensino Mútuo era superior ao do Ensino Individual.

Conforme já mencionado, no texto da Lei de 1836 há referência acerca da existência de dois métodos de ensino diferentes no ensino público de Santa Catarina: o individual e o mútuo.

Segundo Pierre Lesage o ensino individual: 
Consiste em fazer ler, escrever, calcular cada aluno separadamente, um após o outro, de maneira que, quando um recita a lição, os demais trabalham em silêncio e sozinhos. O professor dedica poucos minutos a cada aluno. $\mathrm{O}$ emprego de meios coercitivos garante o silêncio e o trabalho. Não existe um programa a ser adotado, e as variações, de escola para escola, são imensas (apud BASTOS, 1999, p. 96).

O método de ensino individual seria especialmente indicado para classes de leitura e supõe intervenção orientada pela especificidade do grau de adiantamento de cada aluno; aqui o agente de ensino é somente o professor (BARRA, 2001).

$\mathrm{Na}$ Província de Santa Catarina, no início do século XIX, o ensino individual era prescrito na legislação, especificamente para áreas rurais; onde poucos alunos iam à escola, era difícil agrupá-los e a precariedade de materiais era grande. $\mathrm{O}$ trabalho consistia em ensinar a ler, a escrever e a fazer cálculos. A Lei $\mathrm{n}^{\circ}$ 93, de 27 de abril de 1838, estabeleceu diretamente para a professora da então recém-criada "Escola para Meninas na Villa de São José" que esta deveria ensinar pelo ensino individual. Conforme o texto, ela "será obrigada a ensinar a ler, escrever, a pratica das quatro primarias operações de arithmetica, a doutrina christã, e as prendas domesticas necessárias à boa educação feminil" (COLLEÇÃO DAS LEIS DA PROVÍNCIA DE SANTA CATHARINA DOS ANOS DE 1835 a 1853, p. 193).

Conforme Maria Helena Câmara Bastos, que fez um estudo ${ }^{8}$ minucioso sobre o ensino mútuo e sua presença no Brasil, este método de ensino teria sido sistematizado separadamente por André Bell (1735-1832) e por Joseph Lancaster $^{9}$ (1778-1838). Este último criou uma escola gratuita para 1.200 crianças pobres em Londres. Como não havia recursos para pagar professores, decidiu dividir os alunos por classes e colocar em cada classe um monitor - aluno que se destacava dos demais - com conhecimento superior, o qual trabalhava sob supervisão direta do professor. Dessa maneira, podia-se ensinar um grande número de alunos com custo reduzido (BASTOS, 1999).

Já André Bell ${ }^{10}$ desenvolveu o método nas Índias Inglesas, em Madras, onde dirigiu um orfanato. Como também não tinha verba para pagar professores, escolheu seus melhores alunos para serem monitores e ensinarem aos demais os

8 Ver especialmente BASTOS, Maria Helena Camara. O Ensino Mútuo no Brasil (18081827). In: BASTOS, Maria Helena Câmara; FARIA FILHO, Luciano Mendes de (Orgs.). A Escola Elementar no Século XIX: o método monitorial/mútuo. Passo Fundo/RS: EDIUPF, 1999. p. 95-118).

9 Joseph Lancaster pertencia à seita dos quacres (Seita Religiosa Protestante Inglesa - a Sociedade dos Amigos) (BARRA, 2001).

10 André Bell era médico e pastor anglicano (BASTOS, 1999, p. 97). 
conhecimentos que haviam aprendido com o professor. Bastos afirma que durante sete anos ele "conseguiu instruir duas centenas de alunos" (BASTOS, 1999, p. 97). Bell teria introduzido a areia para facilitar o ensino da escrita. Ele teria presenciado "crianças hindus que estudavam sob direção de um de seus camaradas e escreviam com os dedos sobre a areia" (DEMKÉS, apud BARRA, 2001, p. 14). No entanto, foi Lancaster que sugeriu que "a areia deveria ser colocada em cima da mesa, em um espaço 'pintado de preto', para que, quando os 'meninos' fizessem 'as lêtras na arêa branca, o chão preto'mostrasse 'a figura"' (BARRA, 2001, p. 14). A função das "mesas de areia" seria servir como uma espécie de lousa, onde se escrevia e depois se apagava. Conforme Barra, "o alisamento da areia eliminaria os traços. Para ser alisada com rapidez e perfeição, a areia deveria estar 'bem sêcca'. Um 'bornidor' era usado pelo decurião para alisar a areia de cada um dos alunos da classe" (BARRA, 2001, p. 14). De acordo com a autora, esses procedimentos geravam alguns problemas, principalmente com relação ao comportamento dos alunos, pois, enquanto se alisava a areia de um, os outros ficavam ociosos. Esta é apontada como uma das razões para que as mesas de areia fossem, mais tarde, substituídas pelas ardósias.

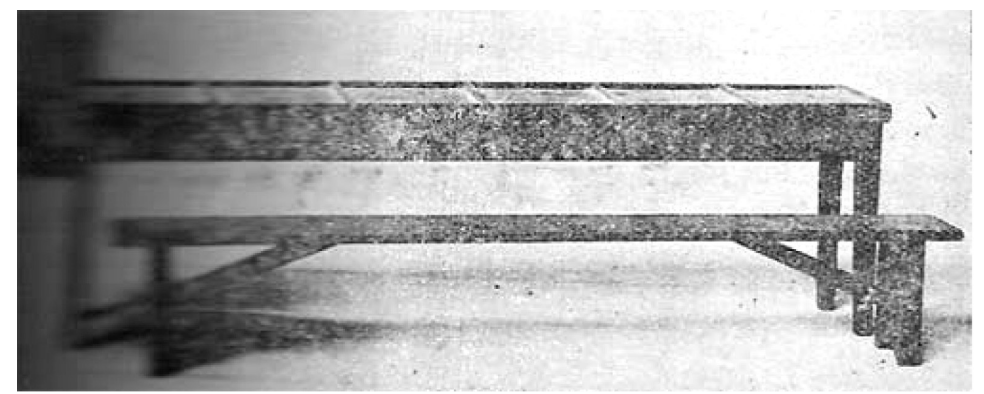

FIGURA $2^{11}$ - MESA DE AREIA

FONTE: Revista do Centro de Educação/UFSM, Disponível em: <http://coralx.ufsm.br/revce/>.

Depois que as crianças aprendem a desenhar o alfabeto na areia, começam a soletrar escrevendo... Porém, não se mostra mais ao aluno a sílaba a ser escrita, mas só se pronuncia e cada um, ouvindo-a, escreve-a. Chegados às palavras inteiras, o monitor pronuncia primeiro as letras, depois as sílabas e, em seguida, a palavra inteira, e o aluno enquanto escreve precisa soletrar

11 Mesa de areia, do método Lancaster. Elomar Tambara. O ensino mútuo na Província Cisplatina. Edição: 2005 - v. 30 - n. 02. Revista do Centro de Educação/UFSM, Santa Maria. Disponível em: <http://coralx.ufsm.br/revce/>. Acesso: 15/01/2009. 
em voz baixa... E se tem a vantagem de que muitos alunos podem soletrar juntos sem se perturbarem mutuamente (HAMEL, apud MANACORDA, 1989 , p. 259).

Em geral, os métodos de ensino indicavam como deveria ser a sala de aula. A de ensino mútuo deveria ser:

Grande rectângulo, para que todas as mesas estivessem de frente para um dos topos da sala onde se encontrava um estrado elevado, local onde se colocava a mesa do professor e de onde este podia com facilidade ver toda a sala e descobrir quem estava ou não com atenção, dando ordens, comandando a sala como um capitão na proa de um navio. Era com certeza uma sala imponente e onde reinava uma disciplina como no exército (MACHADO, 2004, p. 43).

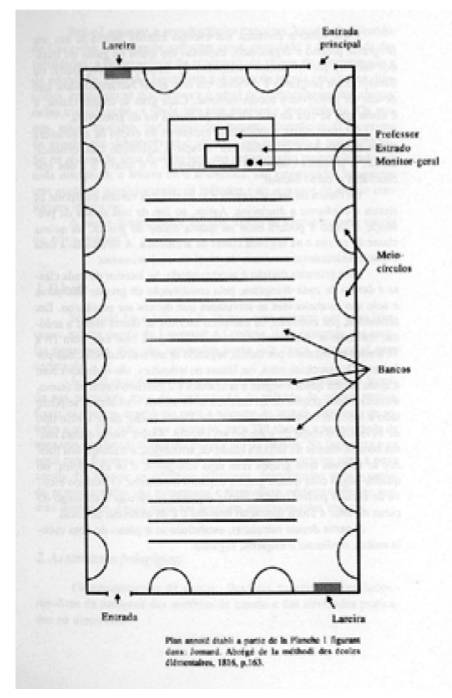

FIGURA 3 - PLANO DE UMA ESCOLA MÚTUA

FONTE: LESAGE, Pierre. A Pedagogia nas Escolas mútuas do Século XIX. In: BASTOS, Maria Helena Câmara; FARIA FILHO, Luciano Mendes de (Orgs.) (1999). A Escola Elementar no Século XIX: o Método monitorial/mútuo. Passo Fundo/RS: EDIUPF, 1999. p. 14. 
Interessante anotar que este formato de sala de aula ainda é atualmente encontrado nas escolas. Quanto às ordens emitidas pelo "capitão" - (professor) -, no método mútuo, os sinais têm muita importância; os alunos devem atender automaticamente. "A escola mútua levará ainda mais longe esse controle dos comportamentos pelo sistema dos sinais a que se tem que reagir imediatamente. Até as ordens verbais devem funcionar como sinalização" (FOUCAULT, 1987, p. 141). Aqui, o professor explica no início da aula aos monitores o que devem ensinar para os alunos e estes ficam responsáveis em repassar aos demais. O professor permanece sentado no fundo da sala, tendo pouco contato com os alunos.

Em Santa Catarina, o interesse da Província com o ensino mútuo se revela na Lei $\mathrm{n}^{\circ} 136$, de 14 de abril de 1840 , que autoriza seu presidente a mandar buscar um professor de Primeiras Letras no Rio de Janeiro, para que ensine pelo método de Lancaster. Segundo o artigo $2^{\circ}$, "este Professor virá reger a escola pública de primeiras letras estabelecida na Capital, deverá ensinar: $1 .^{\circ}$ a ler e escrever pelo methodo Lancastiano [sic], cujos principios theoricos e práticos explicará" (COLLEÇÃO DAS LEIS DA PROVÍNCIA DE SANTA CATHARINA DOS ANOS DE 1835 a 1853, p. 263).

No entanto, em 1843 na Lei 214, encontra-se o seguinte texto:

Artigo $1 .^{\circ} \mathrm{O}$ Professor Público de Primeiras Letras da Cidade de Desterro he obrigado a ensinar; $1 .^{\circ}$ Ler e escrever, cujos princípios theoricos e praticos pelo methodo individual: $2^{\circ}$ as quatro operações arithmeticas, quebrados, decimaes, e proporções: $3^{\circ}$ Noções geraes de Geometria, theorica e pratica: $4^{\circ}$ Grammatica da lingoa Nacional: $5^{\circ}$ Elementos de Geogaphia: $6^{\circ}$ Os princípios da moral Chistã, e da Religião do Estado.

Todos os demais Professores Públicos da Província ensinarão do mesmo modo pelo methodo individual porém somente as materias dos parágrafos, $1 .^{\circ}, 2^{\circ}, 4^{\circ}$ e $6 .^{\circ}$ do prezente artigo (COLLEÇÃO DAS LEIS DA PROVÍNCIA DE SANTA CATHARINA DOS ANOS DE 1835 a 1853, p. 151).

Desse modo, o método de ensino oficial na província de Santa Catarina passou a ser o método de ensino individual, porém existiam diferenças entre o que se ensinava na capital, a Cidade de Desterro - que seria algo mais elaborado, com mais conteúdos - e o que se ensinava no restante da província.

Em 1875 (Lei 776), volta-se a tratar sobre o que ensinar nas escolas e também se percebem as diferenças entre as escolas de Desterro e escola rurais das Villas e Freguezias: 
Artigo 4. ${ }^{\circ}$ : São escolas urbanas da Capital e Cidades da Província, e comprehenderão as seguintes diciplinas:

Artes de ler e escrever e contar scientificamente, com o novo systema de pesos e medidas Noções de Civilidade, de Moral e Doutrina Christã.

Grammatica portugueza, Noções de Historia e Geographia Pátrias, Leituras correntes da Constituição e Desenho linear.

Artigo 5. ${ }^{\circ}$ : São escolas as das Villas, Freguezias e Arrayaes e comprehenderão as seguintes disciplinas:

Ler, escrever ditada com practica de orthographia, contar as quatro especiais operações em inteiros e decimaes e conhecimento pratico das proporções, bem como do novo systema de peso e medidas. Noções de Civilidade, de Moral e Doutrina Christã e leitura da Constituição.

Agricultura adoptada ao melhoramento da nossa lavoura (LEIS DA PROVINCIA 1871 a 1875, p. 59-60).

Este recorte registra a existência, patrocinada pelo Estado, de diferença entre o ensino oferecido nos espaços urbanos e aquele destinado à população do meio rural. As escolas urbanas ofereceriam um ensino mais completo e complexo, com mais conteúdos; as rurais ministrariam menos conteúdos, centrando preocupação em ensinar agricultura para melhoria das lavouras. A diferença também é atestada na remuneração dos professores. A Lei ${ }^{\circ} 776$ estipula o ordenado de 600\$000 tanto para professores de escolas urbanas quanto para professores de escolas rurais; entretanto, a diferença está na gratificação - $400 \$ 000$ para cadeiras urbanas e $300 \$ 000$ para rurais.

O relatório apresentado ao $1^{\circ}$ vice-presidente da Província de Santa Catarina, em 1863, mostra a precariedade das escolas, dos professores e também do método de ensino adotado:

A falta quasi geral de pessoal habilitado, o pouco zelo com que são desempenhados os deveres do magistério, a indolencia, ou indifferentismo da maior parte dos pais em procurarem a seus filhos os elementos indispensáveis da educação intellectual; a defficiencia de uma inspeção deligente e constante de força e autoridade de acção nos centros parciais de ensino e a pouca uniformidade do ensino ou systema de que faz uso, são obstaculos que impedem o seu progresso (RELATÓRIO ENCAMINHADO VICE-PRESIDENTE 1863, p. 4).

De acordo com esse relatório, vários professores não tinham formação e não sabiam como aplicar os métodos de ensino. 
Já o relatório de 1885, encaminhado ao vice-presidente da Província, mostra que na cidade de Joinville a instrução primária mereceu louvor, e também mostra indícios da aplicação do método de ensino mútuo:

\begin{abstract}
D'entre todas as escolas de instrução primária, muitas das quaes tive occasião de visitar, assistindo às lições dos professores, devo destacar com louvor a escola pública mixta da cidade de Joinville dirigida há 24 annos pelo illustrado e virtuoso Padre Carlos Boergeshausen, vigário da freguezia. Conta com 377 alumnos matriculados, sendo a freqüência de 247. E' dividida em cinco classes, que trabalham em quatro salões espaçosos e bem arejados, sendo o professor auxiliado por quatro adjunctos, dos quaes dous são contractados pelo próprio professor, assim como a adjuncta que dirigi a classe infantil (RELATÓRIO ENCAMINHADO AO VICE-PRESIDENTE 1885, p. 26).
\end{abstract}

Nota-se, na citação, que o método aplicado seria o mútuo, pois havia somente um professor com quatro "adjunctos", os quais seriam monitores que auxiliavam o professor frente a cinco classes. Interessante perceber a presença desse método de ensino naquela cidade (de colonização alemã) e que rendia bons elogios de quem visitava as classes. O relatório ainda informa que essa escola tinha "a mobília precisa", dando a entender, pelo menos ao inspetor que o estava relatando, que o mobiliário escolar estava adequado. Contudo, esta não era a realidade da maior parte das escolas catarinenses, pois há muitas reclamações por parte dos inspetores em outros relatórios.

O relato abaixo é de uma ex-aluna, ingressante na escola ainda na primeira década do século XX, que mais tarde integraria o corpo discente da Escola Normal, tornando-se, após a viuvez, professora primária do magistério público catarinense. A escola de sua infância:

... funcionava num cômodo da casa de Dona Liça; não havia carteiras individuais, mas compridos bancos sem encosto, onde as crianças ficavam sentadas, lado a lado, horas a fio. Todas juntas, independente de idade e sexo. Eram alfabetizadas pela carta do ABC, método bê-a-bá ou da silabação, precisavam decorar textos imensos, retirados dos compêndios e, quando não conseguiam ou saíam da linha por qualquer outro motivo, eram surpreendidas com a prática do bolo, castigo por meio da palmatória (TEIVE, 2008, p. 47). 
O trecho mencionado não deixa claro o método de ensino que Dona Liça utilizava. Supõe-se que era o Mútuo ou o Individual, pois a memorização (presente tanto no individual quanto no mútuo) e a disciplina rígida (nota-se mais fortemente no mútuo) reveladas no relato sugerem que um dos dois métodos estava sendo aplicado na sala de aula frequentada por Dona Passinha. Interessante notar, no relato, que não havia carteiras escolares e sim "bancos sem encosto".

Embora o Relatório do Inspetor Escolar encaminhado ao Vice-Presidente da Província em 1885 mostre que em Joinville existia um bom mobiliário para os alunos sentarem, o que se verificou nesta pesquisa é que a materialidade das escolas catarinenses era precária. As crianças sentavam em lugares improvisados e até mesmo em "tocos" de madeira, muitas vezes sem conforto, embora os métodos de ensino recomendassem outra estrutura material.

Os Grupos Escolares implantados em Santa Catarina no início do século XX, sob a vigência da Reforma da Instrução Pública de 1911, articulada e coordenada pelo professor paulista Orestes Guimarães ${ }^{12}$, congregarão o ideal de escola em termos de estrutura material. Aqui, sim, parece que toda a sorte de mobília e recursos pedagógicos será adquirida e estrategicamente ordenada em edifícios suntuosos, que anunciaram um projeto de escola nunca alcançado pela maioria da população.

\section{BIBIOGRAFIA CONSULTADA}

BARRA, Valdeniza Maria da. Da Pedra ao Pó: o itinerário da lousa na escola paulista do século XIX. Dissertação (Mestrado em Educação: História e Filosofia da Educação) - Pontifícia Universidade Católica de São Paulo, São Paulo, 2001.

BASTOS, Maria Helena Camara. O Ensino Mútuo no Brasil (1808-1827). In: BASTOS, Maria Helena Câmara; FARIA FILHO, Luciano Mendes de (Orgs.). A Escola Elementar no Século XIX: O Método monitorial/mútuo. Passo Fundo/RS: EDIUPF, 1999. p. 95-118.

BASTOS, Maria Helena Câmara; FARIA FILHO, Luciano Mendes de (Orgs.). $A$ Escola Elementar no Século XIX: O Método monitorial/mútuo. Passo Fundo/RS: EDIUPF, 1999.

BAUDRILLARD, Jean. O Sistema dos Objetos. 4. ed. $3^{\text {a }}$ reimpressão. Tradução de Zulmira Ribeiro Tavares. São Paulo: Perspectiva, 2006.

12 Reformador do ensino cedido ao governo catarinense pelo Estado de São Paulo. 
FERNANDES, Rogério. A história da educação no Brasil e em Portugal. Caminhos cruzados. Revista Brasileira de Educação, n. 7, jan./fev./mar/abr. 1998. Disponível em: <http://www.anped.org.br/rbe/rbedigital/RBDE07/RBDE07_03_ROGERIO_ FERNANDES.pdf $>$. Acesso em: 23/12/2008.

FIORI, Neide Almeida. Aspectos da Evolução do Ensino Público: Ensino público e política de assimilação cultural no Estado de Santa Catarina nos períodos Imperial e Republicano. Florianópolis/SC: Edeme, 1975.

FOUCAULT, Michel. Vigiar e punir: nascimento da prisão. Petrópolis: Vozes, 1987.

GASPAR da SILVA, Vera Lucia. Vitrines da República: Os Grupos Escolares em Santa Catarina (1889-1930). In: VIDAL, Diana Gonçalves (Org.). Grupos Escolares: cultura escolar primária e escolarização da infância no Brasil (1893-1971). Campinas, São Paulo: Mercado de Letras, 2006. p. 341-376.

HÉBRARD, Jean. Por uma Bibliografia Material das Escritas Ordinárias: o espaço gráfico do caderno escolar (França - Séculos XIX e XX). Revista Brasileira de História da Educação, SBHE, n. 1, p. 115-142, jan./jun. 2001.

LESAGE, Pierre. A Pedagogia nas Escolas mútuas do Século XIX. In: BASTOS, Maria Helena Câmara; FARIA FILHO, Luciano Mendes de (Orgs.). A Escola Elementar no Século XIX: O Método monitorial/mútuo. Passo Fundo/RS: EDIUPF, 1999, p. 9-24.

MACHADO, Maria de Fátima Costa Monteiro de Sá. Maneiras de sentar: Contributo para a história das carteiras escolares do ensino primário em Portugal (1835 -1970). Dissertação (Mestrado em Ciência da Educação) - Universidade de Lisboa, Lisboa, 2004.

MANACORDA, Mario Alighiero. História da Educação. Da Antiguidade aos nossos dias. São Paulo: Cortez / Autores Associados, 1989.

PATRÍCIO Ângela. Notas sobre o Mobiliário escolar em Portugal no século XX: Lisboa, 2006. Disponível em: $<$ http://www.educ.fc.ul.pt/docentes/opombo/hfe/lugares/ mobiliario/ hfe.htm >. Acesso em: 20/6/2007.

PESEZ, Jean-Marie. História da cultura material. In: LEGOFF, Jacques. A História Nova. São Paulo: Martins Fontes, 2005.

ROCHE, Daniel. História das coisas banais. Tradução de Telma Costa. Lisboa: Editorial Teorema, 1998.

SOUZA, Gizele de. Espaço e mobília escolar na Instrução Pública Paranaense no limiar do Século XX. Intermeio: Revista do Mestrado em Educação, Campo Grande, v. 12, n. 23 , p. $70-78,2006$. 
SOUZA, Rosa Fátima de. História da cultura material escolar: um balanço inicial. In: BENCOSTA, Marcus Levy (Org.). Culturas escolares, saberes e práticas educativas: itinerários históricos. São Paulo: Cortez, 2007.

TAMBARA, Elomar. O ensino mútuo na Província Cisplatina. Revista do Centro de Educação/UFSM, Santa Maria, v. 30, n. 02, 2005. Disponível em: <http://coralx.ufsm. br/revce/>. Acesso: 15/01/2009.

TEIVE, Gladys Mary Ghizoni. Uma vez normalista, sempre normalista: cultura escolar e produção de um habitus pedagógico - (Escola Normal Catarinense - 1911/1935). Florianópolis: Insular, 2008.

VALDEMARIN, Vera Teresa. Lições de coisas: concepção científica e projeto modernizador para a sociedade. Cadernos CEDES, Campinas/SP, v.52, p.74-87, 2000.

VINCENT, Guy; LAHIRE, Bernard; THIN, Daniel. Sobre a história e a teoria da forma escolar. Educação em Revista, Belo Horizonte/MG: Faculdade de Educação da Universidade Federal de Minas Gerais, n. 33, p. 7-47, jun. 2001.

VIÑAO FRAGO, Antonio; ESCOLANO BENITO, Agustín. Currículo, Espaço e Subjetividade: a arquitetura como programa. Rio de Janeiro: DP\&, 2001.

\section{FONTES CONSULTADAS}

ASSIS, Machado de. Várias histórias. Guarulhos: GERMAPE, 2005.

AURÉLIO. Minidicionário da língua portuguesa. Rio de Janeiro: Nova Fronteira, 1985. Isto.

PROFESSORA MARIA DOS PASSOS OLIVEIRA (Dona Passinha). Entrevista concedida a Ana Maria de Brito Gouvêa e Vera Lucia Gaspar da Silva, vinculadas ao projeto "Resgate da História e da Cultura Material da Escola Catarinense - Museu da Escola Catarinense", coordenado pela professora Maria da Graça Machado Vandresen. Florianópolis, 29 de julho de 1999. (Entrevista disponível no Acervo de História Oral do Museu da Escola Catarinense).

SANTA CATARINA. Pareceres, 1835/1841. Centro de Memória da Assembléia Legislativa, doc. 33, p. 21.

SANTA CATARINA. Colleção das Leis da Província de Santa Catharina dos anos de 1835/1853. Biblioteca Pública do Estado de Santa Catarina. 
SANTA CATARINA. Colleção das Leis da Província de Santa Catharina dos anos de 1871/1875. Biblioteca Pública do Estado de Santa Catarina.

SANTA CATARINA. Relatório. Relatório dirigido ao Vice-Presidente da Província de 1863. Arquivo Público do Estado de Santa Catarina.

SANTA CATARINA. Relatório. Relatório dirigido ao Vice-Presidente da Província de 1885. Arquivo Público do Estado de Santa Catarina.

Texto recebido em 17 de agosto de 2009.

Texto aprovado em 22 de fevereiro de 2010. 